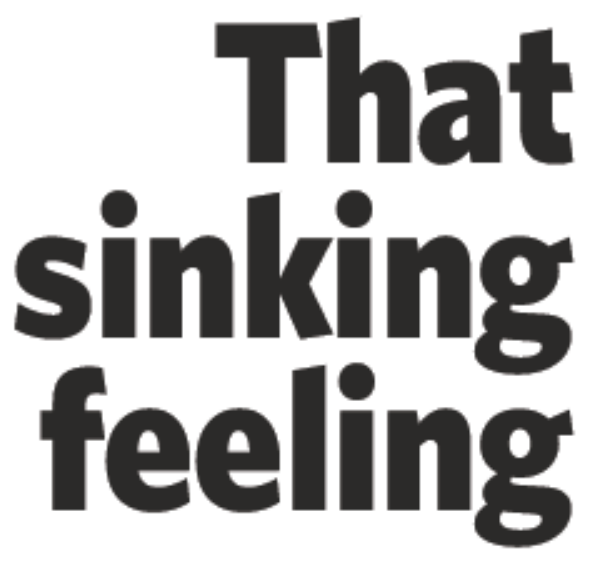

Siberia's vast forests absorb huge quantities of carbon from the atmosphere. But how much, and will they continue to do so in a warming world? Quirin Schiermeier speaks to the carbon accountants.

t took just one Siberian heatwave to temporarily wipe out most of the gains made by the Kyoto Protocol on climate change. In the summer of 2003, wildfires raced across the region, incinerating an area of some 22 million hectares: slightly smaller than the state of Oregon. As the trees went up in smoke, they released about 250 million tonnes of carbon into the atmosphere - roughly the same amount as industrialized countries have pledged to cut from their emissions by 2012 under the Kyoto agreement.

Natural releases of carbon - from wild fires, thawing permafrost or drained peatlands - aren't covered by the Kyoto Protocol, which aims to cut emissions from the burning of fossil fuels. But if future political agreements are to save us from a dimate catastrophe, experts agree that we need a much better understanding of natural carbon sources and sinks, and whether they can be manipulated to help put a brake on global warming.

Siberia looms large in this debate, its vast forests - or taiga — are a potentially huge sink for greenhouse gases such as carbon dioxide. Yet so little is known about Siberia's role in the global carbon cycle that researchers have been scrambling to gather basic data. For the past few years, scientists have fanned out across the taiga, working in two projects aimed at quantifying Siberia's carbon budget.

${ }^{\alpha}$ We need to understand what will happen when climate change really kicks off," says Wolfgang Lucht, a biosphere researcher at the Potsdam Institute for Climate Impact Research in Germany. "When, in 30 years, governments ask us how the world has changed, we must be able to provide answers."

To that end, 14 institutes have taken part in the Siberia-II, a European Union-funded

\author{
IMAGE \\ UNAVAILABLE \\ FOR COPYRIGHT \\ REASONS
}

Taiga, taiga, burning bright: following huge forest fires in Siberia (above), researchers have been monitoring the amount of greenhouse gases released by the trees (left).

initiative to quantify the greenhouse-gas budget of a 2-million-square-kilometre area in central Siberia. A complementary project, called the Terrestrial Carbon Observing System, or TCOS, is providing more detailed, realtime measurements of carbon fluxes between Siberian forests and the lower levels of the atmosphere. Both projects, now approaching completion, have yielded a wealth of data. And one fact stands out: Siberia's taiga is a more modest carbon sink than previously thought.

\section{Lie of the land}

These vast forests are by far the largest terrestrial carbon reservoir in the Northern Hemisphere. Unlike tropical rain forests, where logging is the main disturbance to the carbon cycle, changes in the carbon balance in the taiga are being driven mainly by climate change. This makes these forests an ideal place to study the interplay between climate and landscape.

Siberia is also a climatic hot spot, with short warm summers and extremely long, cold winters. Temperatures vary greatly from year to year, but on average, surface temperatures in central Siberia have increased by up to $3{ }^{\circ} \mathrm{C}$ since 1960 - three to four times more than the global average. 


\section{IMAGE}

\section{UNAVAILABLE FOR COPYRIGHT REASONS}

In a warmed world of the future, Siberia might see some short-term benefits. The warmer temperatures have already sparked a greening trend: spring arrives sooner and buds and leaves appear earlier in the growing season. To some extent, this counteracts the greenhouse effect, as growing plants remove carbon dioxide from the atmosphere through photosynthesis. Some Russian scientists and policymakers critical of the Kyoto Protocol daim that a warmer climate will have positive effects on plant productivity and agriculture in Russia ${ }^{1}$.

\section{Tinderbox}

But the growth spurt is unlikely to continue for ever, says Lucht. "At some point, even though we don't know when, Siberian forests might begin to suffer from heat stress and die," he explains. And thelong-term picture isn't much better. Although the natural fluctuations are large, and model predictions uncertain, many scientists believe that summers will become warmer and drier in Siberia. This would favour the outbreak of fires, releasing carbon at an even greater rate, says Heiko Baltzer, head of Earth observation at the Centre for Ecology and Hydrology in Monks Wood, UK.

Recent research shows that a warmer climate could also enhance soil respiration, permafrost thawing and the decomposition of organic matter in peat, moors and bogs - all of which result in additional release of carbon $^{23}$. By the middle of this century, the planet's terrestrial biosphere could turn from a carbon sink into a carbon source ${ }^{4}-$ and global warming would step up a gear.

Siberia-II has tried to document the current state of carbon exchange in the region's forests so that future changes can be carefully measured. But it hasn't been an easy task. Project scientists have learned that at least one crucial bit of information is missing the total biomass contained in Siberias forests and soils. Satellites can monitor changes in land cover, but they provide little or no information about the actual volume of stems, roots and leaves present.

\section{Lost in a forest}

So forest inventories are crucial. Unfortunately, they are scarce for Siberia, and those that do exist are full of gaps. "Most data from Russian inventories are obsolete, and some are plain wrong," says Anatoly Shvidenko, a forest ecologist with the International Institute for Applied Systems Analysis (IIASA) in Laxen-

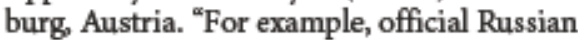
statistics either don't account for the large forest fires in 1998 and 2003, or substantially underestimate them," he says.

But Shvidenko, former head of the All-Russian Scientific Research Information Center for Forest Resources in Moscow, is an old hand at dealing with Russian sources. With the help of two partner institutes in Irkutsk and Krasnojarsk, he has touted round and collected together what he believes are the most accurate data on forest inventories, discarding information he knew to be outdated or misleading. This newly compiled inventory will be indispensable for validating remote-sensing data and the results of computer models.

The Siberia-II researchers have also developed mathematical models to transform raw satellite data into real-
"Uncertainties about the carbon flux used to be in the range of plus or minus $100 \%$ - now we may have halved the margin of error." - Sten Nilsson tified, but the two projects have made scientists more confident that they can account for the carbon budget for an area this large.

The preliminary findings have whetted scientists' appetite for more. In particular, Christiane Schmullius, a remote-sensing expert at Jena University in Germany, who coordinated Siberia-II, wants to use radar to monitor biomass from space. The European Space Agency's Envisat satellite carries a radar sensor, but its ability to determine the height and density of vegetation is limited.

"We have seen in Siberia that remote sensing has the potential to provide all the information needed for full greenhouse-gas accounting," says Schmullius. NASA plans to take advantage of that fact for its Orbiting Carbon Observatory mission, set to launch in 2008. This satellite will make global carbon dioxide maps twice a month, at a level of detail that would allow it to monitor changes such as those triggered by Siberian wildfires.

\section{Branching out}

Siberia-II has substantially helped to reduce the uncertainties about carbon flux, says Sten Nilsson, a forest scientist at the IIASA. "Uncertainties used to be in the range of plus or minus $100 \%$," he says. "Now we may have halved the margin of error."

Buoyed by the early results, Germany's Max Planck Society has funded an ambitious follow-up project to establish in greater detail how greenhouse gases flow between Siberian forests and the atmosphere. Together with Russian partners, the society is building a 300 metre-high measurement tower near the Yenisey River in central Siberia. The Zotino Tall Tower Observatory, or Zotto, will become operational next year, fully equipped with high-precision tools to measure a variety of greenhouse world information, such as how much of the taiga is covered by plants or snow. This information has been checked by scientists heading out into the field to confirm that the satellites were correctly interpreting what they saw on the ground. In addition, team members have produced new maps, which can be used to improve the accuracy of computer models about vegetation in Siberia.

The TCOS project, meanwhile, focused on the flux of carbon dioxide between the forest and the atmosphere. Six observational towers, each placed in a separate ecosystem, measured gases in the air up to a height of 30 metres. Once or twice a month, scientists flew aircraft through the lower 2 kilometres of the atmosphere, to measure carbon dioxide levels.

Early results have shown not only that the taiga is a relatively modest sink for carbon, but that it may also give off more methane - a strong greenhouse gas - than previously thought. Both effects have yet to be fully quan- gases. Zotto will also have an underground laboratory, buried to protect it from climate extremes, for in situ analysis.

Zotto should help constrain assumptions on how much more greenhouse gas the taiga is capable of sucking up, says Martin Heimann, an atmospheric physicist at the Max Planck Institute for Biogeochemistry in Jena, who coordinates TCOS. Such information, accumulated piece by piece, helps to flesh out the full picture of carbon accounting and so could shape the direction of future climate policies. It may prove to be possible to sort the wood from the trees after all.

Quirin Schiermeier is Nature's German correspondent.

1. Schiermelex, Q.\& MacWilliams B. Natue 431,12-13(2004).

2. Frey, K.E.\&. Smith, L. C.Geophys Res. Lett. 32, L09401 (2005).

3. Knorc, W, Prentice, I.C.,House, L L \& Holland E A. Nature 433,298-301 (2005)

4. Cox, P.M, Betts, R.A, Jones, C. D, Spall, S.A.\& Totterdell, I. I Nature 408, 184-187 (2000) 